\title{
Localizing small nodules: Is it time for a randomized trial?
}

\author{
Nasser Altorki, MD, and Eugene Shostak, MD
}

\footnotetext{
From the Division of Thoracic Surgery, Department of Cardiothoracic Surgery, Weill Cornell Medicine-New York Presbyterian Hospital, New York, NY.

Disclosures: Authors have nothing to disclose with regard to commercial support.

Received for publication Jan 27, 2017; accepted for publication Feb 17, 2017; available ahead of print March 23 , 2017.

Address for reprints: Nasser Altorki, MD, Weill Cornell-New York Presbyterian Hospital, 525 East 68th St, New York, NY (E-mail: nkaltork@med.cornell.edu).

J Thorac Cardiovasc Surg 2017;153:1591

0022-5223/\$36.00

Copyright (C) 2017 by The American Association for Thoracic Surgery

http://dx.doi.org/10.1016/j.jtcvs.2017.02.037
}

The near ubiquitous use of computed tomography (CT) resulted in the identification of a substantial number of individuals harboring small pulmonary nodules. Fortunately, the overwhelming majority of these nodules have no clinical consequence. However, in a significant minority of people, particularly those in an acknowledged high-risk group, further workup, which may include thoracic surgical evaluation, is unavoidable. The diagnostic challenge posed by these small, barely visible, or palpable solid and nonsolid nodules has given rise to the appealing concept of nodule localization. There are several reported methods of nodule localization, including CT-guided (hook wire/micro-coil/Lipiodol [Guerbet, Princeton, $\mathrm{NJ}]$ ), radionuclide-guided, and endoscopic-guided techniques. In the current issue of the Journal, Abbas and colleagues ${ }^{1}$ report on the use of intraoperative electromagnetic navigational bronchoscopy (ENB) for the purpose of nodule localization. Approximately half of 54 nodules were ground glass with a mean diameter of $13.9 \mathrm{~mm}$. Their technique involved the transbronchial, often combined delivery of methylene blue, indocyanine green, and Isovue (Bracco, Monroe Township, NJ). After localization, patients underwent immediate surgical resection mainly by sublobar robotic techniques. The authors successfully localized $98 \%$ of the nodules, which in turn enabled minimally invasive resections in $96 \%$ of patients. There are several advantages for this approach, including the ability to perform marking immediately before surgery in a single anesthetic event and a lower risk of pneumothorax or pulmonary hemorrhage. Intraoperative bronchoscopic marking also may obviate the need for coordination and possible communication lapses between radiology and surgical services. So, what is the take home message for the practicing thoracic surgeon? Should ENB localization become our preferred method to localize small peripheral nodules? We believe the answer is probably "Not yet." Although ENB localization may have the distinct advantages cited previously, it also can be associated with a steep learning curve, and its universal application may add appreciably to operating room time, thus altering the cost-benefit ratio. Another relatively underappreciated aspect of ENB localization is that it is virtual locali-

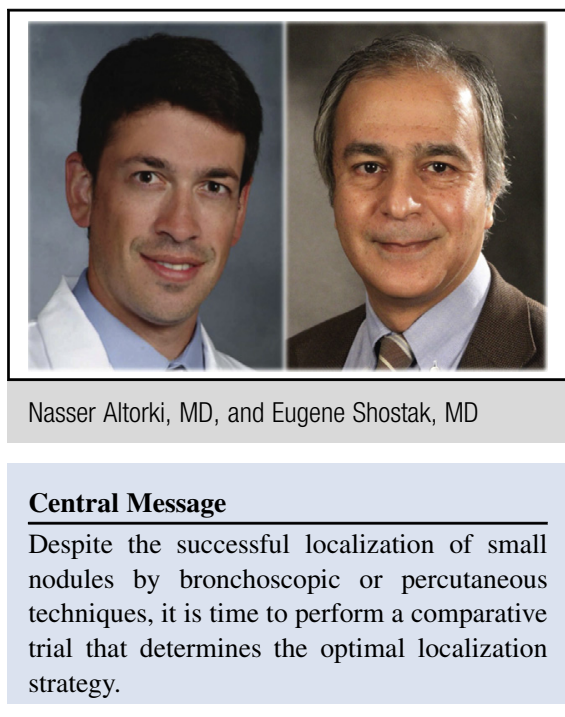

See Article page 1581.

zation that leaves the operator with a distinct lack of certainty as to whether a nodule has actually been localized. The competing approach, CT-guided localization, is associated with successful nodule localization in $94 \%$ to $98 \%$ of patients but at the expense of higher, yet manageable, rates of pneumothoraces, pulmonary bleeding, and wire dislodgments or migration. The question thus remains: Which of the 2 modalities should we preferentially adopt? This is precisely the question that begs a randomized comparison in pursuit of an evidencebased answer. First, it is our opinion that legitimate equipoise exists between the 2 approaches. Second, the primary end point for a potential randomized trial is well defined and immediately discernible, rendering such a trial "easy" to accomplish and well within the purview of our specialty. Such a trial should enroll patients with peripheral nodules that are clearly within size ranges and consistencies universally acknowledged to be neither visible nor palpable. It also should exclude patients harboring nodules located within small pulmonary segments that can be easily excised with diagnostic and potential therapeutic intent. The work by Abbas and others ${ }^{1}$ is a good example of how thoracic surgeons can adopt and adapt endoscopic techniques to advance our specialty and benefit our patients. Now it is time to move the field a bit forward.

\section{Reference}

1. Abbas A, Kadakia S, Ambur V, Muro K, Kaiser L. Intraoperative electromagnetic navigational bronchoscopic localization of small, deep, or subsolid pulmonary nodules. J Thorac Cradiovasc Surg. 2017;153:1581-90. 